\title{
Energy conversion and efficiency in turboshaft engines
}

\author{
Cristian Dobromirescu ${ }^{1}$, and Valeriu Vilag, ${ }^{1 *}$ \\ ${ }^{1}$ Research and development institute for gas turbines COMOTI, Aviation and industrial turbines. Gas-turbines assembly department, \\ 220 D Iuliu Maniu Bd., sector 6, Bucharest Romania
}

\begin{abstract}
This paper discusses the methods of energy conversion in a turboshaft engine. Those methods cover the thermodynamic cycle and the engine performances, the possible energy sources and their impact on environment as well as the optimal solutions for maximum efficiency in regards to turbine design and application. The paper also analyzes the constructive solutions that limit the efficiency and performances of turboshaft engines. For the purpose of this paper a gas-turbine design task is performed on an existing engine to appreciate the methods presented. In the final part of this paper it is concluded that in order to design an engine it is necessary to balance the thermodynamic aspects, for maximum efficiency, and the constructive elements, so that the engine can be manufactured.
\end{abstract}

\section{Introduction}

Since the creation of the first internal combustion engine it is a top priority to use as much energy and as efficiently as possible [1]. Thus, the study of energy conversion and energy efficiency is very important and many technical details with recommendation and even simple design examples for the entire engine or for the particular components exists $[2,3]$. More, the methods for component design, especially the turbine, were extended for other use such as turbo-pump assembly in rocket applications [4].

The reasons range from building more powerful and capable engines to lowering pollution and fossil fuel consumption. The energy conversion is a complex process and optimizing it can be a difficult task. In the aerospace industry this optimization is essential. Some of the reasons for this are:

- Weight reduction of the aircraft components as well as lowering the fuel quantity on board;

- Lowering the flight cost by fuel consumption reduction;

- The reduction of gas emissions;

- The research of new materials.

For the optimization to be realized it is necessary to understand the energy conversion inside the engine. The energy conversion is best observed in an application. For this paper the application is the design of a gas turbine.

\section{Energy conversion}

The forms the energy takes in the turboshaft engine are mainly:

- Heat;

- Work;

- Kinetic energy;

* Corresponding author: valeriu.vilag@ $@$ comoti.ro

\section{- Pressure.}

The source of energy for the engine is the fuel. For the combustion to take place in optimal conditions, or at all at high altitudes, it is necessary to increase the pressure of the intake air through a compressor. The compressor consumes work and increases the potential energy of the air by raising its pressure. Next, the heat released by the fuel combustion rises the temperature of the now burnt gases and increases the other type of potential energy. The work consumed by the compressor comes from a turbine that absorbs a portion of energy from the burnt gases. Then the remaining energy can be used to either eject the gases, through a nozzle with high velocity and create traction directly or use another turbine to power an external consumer like a propeller, an electric generator or a compressor.

This is the basic design of a turbine engine. This construction follows the Brayton cycle, the cycle specific of a constant pressure combustion engine. There are mainly two forms in which this cycle can be calculated: ideal and real. The latter provides better results, although its calculation requires the ideal cycle values and methods to better approximate the results.

The graphic representation of the real cycle of a turbojet engine can be seen in Fig. 1. Each state in the engine, named " $1 *$ ", " $2 *$ " and so on is used for the calculation of the thermodynamic property corresponding to the total entropy. The " $2 * \mathrm{id} "$, " $4 * \mathrm{id}$ " and so on, signifies the ideal cycle state. These are presumed to be calculated through an isentropic transformation and are on an isobar line with the next state of the real cycle.

Each state of the cycle is defined for a section of the engine between two components. The states are:

- $\quad 0^{*}$ - state corresponding to the section before the engine intake; 
- $\quad 1^{*}$ - state corresponding to the section between the intake and the compressor;

$2 *, 2 * \mathrm{id}$ - states corresponding to the section between compressor and the combustion chamber;

- $\quad 3 *$ - state corresponding to the state between the combustion chamber and the compressor turbine;

- $\quad 4 *, 4 *$ id - state corresponding to the section between the compressor turbine and the power turbine or the nozzle;

- $\quad 4 \mathrm{~T}^{*}, 4 \mathrm{~T}^{*} \mathrm{id}$ - state corresponding to the section between the power turbine and the exhaust nozzle, this state is optional and only calculated if a power turbine is present;

- $\quad 5 * \mathrm{id}, 5-$ the state corresponding to the section after exhaust nozzle.

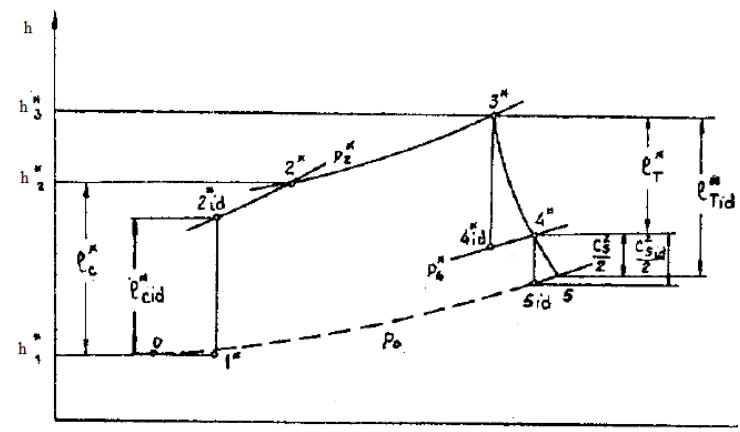

Fig. 1. The real thermodynamic Brayton cycle representation in h-s coordinates, h-enthalpy, s-entropy, with the ideal states represented as well [5].

Each state's thermodynamic properties values were calculated by assuming at least two of the thermodynamic properties and then calculating the rest with use of the aforementioned polynomials. For the burnt gases it is necessary to approximate the composition for better results. All the properties are corresponding to a total enthalpy state:

- $\quad 0^{*}$ - the properties are presumed at sea level at $15^{\circ} \mathrm{C}$ temperature and $101325 \mathrm{~Pa}$ pressure;

- $\quad 1^{*}$ - the flow inside the intake is presumed to be isothermal and with a pressure loss coefficient;

- $\quad 2 *$ id - for the ideal state it is assumed the pressure trough the pressure ratio and that the entropy is identical to state $1 *$;

$2^{*}$ - it is assumed that the pressure is identical to state $2 *$ id and the enthalpy variation, that being the work, inside the compressor for the real state is lower than the variation along the compressor for the ideal state with a compressor efficiency;

$3^{*}$ - the temperature is read from [11] and the pressure is calculated by assuming a loss inside the combustion chamber;

- $\quad 4 * \mathrm{id}-$ similar to state $2 * \mathrm{id}$ it is assumed that the entropy of the state is identical to the entropy of $3 *$ and the work generated by the turbine or the enthalpy variation is greater than the work consumed by the compressor, to compensate for the losses of the shaft transmission and of the flow inside the turbine, so there are assumed two efficiencies a mechanical one and one associated to the turbine;
- $\quad 4 *$ - is calculated by assuming the pressure is identical to $4 *$ id and by assuming that the work is equal only to the value increased by the mechanical efficiency; - $\quad 4 * \mathrm{~T}-$ it is assumed that the pressure is higher than the atmospheric pressure at sea level presumed at state $0^{*}$ by a factor of;

- $\quad 5 * \mathrm{id}-$ it is presumed that the pressure is equal to the atmospheric pressure at that altitude and the entropy is identical to the state $4^{*}$ or $4 * \mathrm{~T}$, in this state the ideal fluid velocity is calculated;

- $\quad 5-$ it is presumed that the pressure is identical $t$ state $5 *$ id and nozzle presents flow imperfections, thus a coefficient must be applied to the speed that resulted in the stat $5 *$ id.

For a better approximation of the thermodynamic values polynomials that calculate the entropy, enthalpy from temperature are used [6]. These polynomials are verified with thermodynamic values from [7]. The difference can be observed in Fig. 2. The polynomials aforementioned are:

$$
\begin{gathered}
i_{\text {air }}^{p=1}(T)=16.7748+0.901616 T+ \\
1.47424 \cdot 10^{-4} T^{2}-1.94118 \cdot 10^{-8} T^{3} \\
S_{\text {air }}^{p=1}(T)=5.64896+4.09865 \cdot 10^{-3} T- \\
2.31958 \cdot 10^{-6} T^{2}+5.45627 \cdot 10^{-10} T^{3} \\
i_{s h}^{p=1}(T)=14.9623+0.920391 T+ \\
2.16424 \cdot 10^{-4} T^{2}-3.10594 \cdot 10^{-8} T^{3} \\
s_{s h}^{p=1}(T)=5.90016+4.01925 \cdot 10^{-3} T- \\
2.10061 \cdot 10^{-6} T^{2}+4.73279 \cdot 10^{-8} T^{3}
\end{gathered}
$$

where $[\mathrm{T}]=\mathrm{K},[\mathrm{i}]=\mathrm{kJ} / \mathrm{kg},[\mathrm{s}]=\mathrm{kJ} / \mathrm{kg} / \mathrm{K}$.
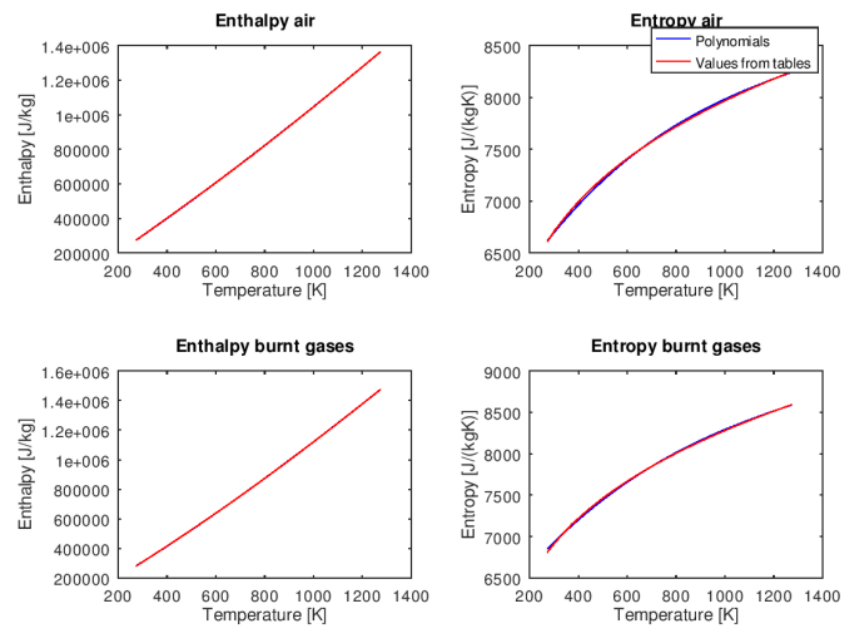

Fig. 2. Comparison between thermodynamic polynomials and values in thermodynamic tables [8].

For the cycle calculation there are two functional parameters that must be assessed. These are the compressor pressure ratio and the air mass flow. For the 
pressure ratio an optimal value can be calculated. The variation of the power provided by the engine in relation to the pressure ratio can be seen in the Fig. 3 .

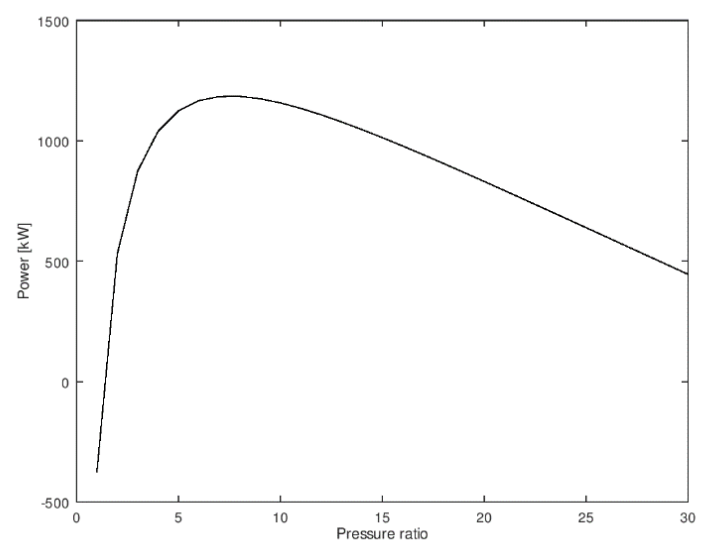

Fig. 3. Power provided by the engine in relation to the compressor pressure ratio [8].

It can be observed that there is a value of the pressure ratio for which the engine power is at peak value. This value is considered to be the optimal pressure ratio. As for the air mass flow the right value for the engine is considered the one for which the calculated power is almost equal to the engine real power.

For the calculation of the said parameters it is necessary to assume a domain of values for pressure ratio and mass flow for the initial calculation. The domain is between the values of 1 and 30 with a step of 1 for both parameters. After an initial result of the parameters is calculated with the assumed domain, further values are calculated with a more restricted domain around the initial result more precise step. The initial and final results calculated are presented in Table 1 .

Table 1. The results of the thermodynamic cycle [8].

\begin{tabular}{|c|c|c|c|}
\hline & $\begin{array}{c}\text { Initial } \\
\text { values }\end{array}$ & Final values & $\begin{array}{c}\text { The } \\
\text { engine } \\
\text { power }\end{array}$ \\
\hline Power [kW] & 1184.4 & 1122 & 1118.5 \\
\hline $\begin{array}{c}\text { Specific fuel } \\
\text { consumption } \\
{[\mathrm{kg} / \mathrm{kW} / \mathrm{hr}]}\end{array}$ & 0.38778 & 0.39337 & 0.3956 \\
\hline $\begin{array}{c}\text { Compressor } \\
\text { pressure ratio }\end{array}$ & 8 & 7.56 & - \\
\hline $\begin{array}{c}\text { Air mass flow } \\
{[\mathrm{kg} / \mathrm{s}]}\end{array}$ & 8 & 7.57 & - \\
\hline
\end{tabular}

The initial and subsequent calculations of the values in Table 1 are realized for the purpose of reaching a closer value of the real engine parameters, which can be read in [11]. That is achieved through comparing the calculated values of the power and fuel consumption with the ones presented in the technical manual of the engine. The obtained values regarding turbine parameters are used later in the paper as input data for detailed design of turbine components. We mention here that this input data can derive from other thermodynamic analysis depending on the turbine application (such as the mentioned turbopump assembly for liquid rocket engine).

All of the thermodynamic cycle states are calculated except the one after the exhaust nozzle. Those states and associated transformations plotted in h-s system are presented in Fig. 4.

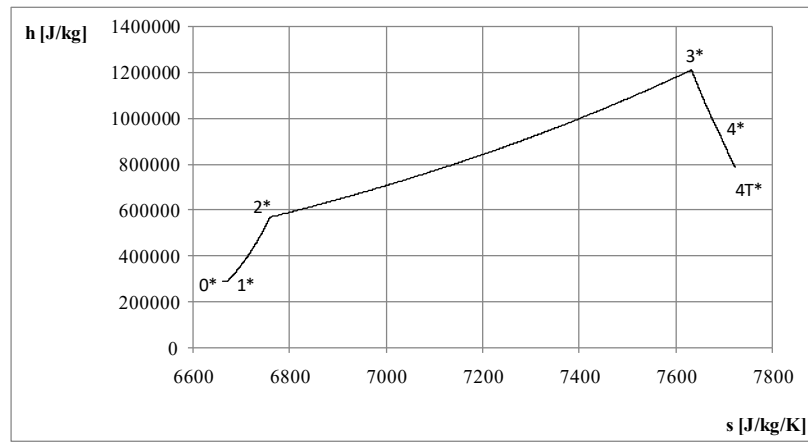

Fig. 4. The calculated thermodynamic cycle states [8].

\section{The design}

So the energy conversion was observed for the engine overall, but for a more specific example the design of a turbine is used. The turbine is a rotary component that extracts energy from a fluid and creates work. The turbines use either kinetic energy or potential energy. The one that uses the kinetic energy is named impulse turbine and it generates all the work just by changing the direction of the flow. The other turbine that is using potential energy is named the reaction turbine and it uses the pressure of the fluid as means to generate work.

For the application in question it is again used the engine TV2-117. The task is designing a power turbine for the engine. The construction chosen is an axial reaction turbine, like the original one used on the engine. This is structured in three parts:

- The velocities diagrams;

- The blade airfoil geometrical design;

- The strength and vibrations calculations of the blade.

The velocities diagrams show the change in direction and magnitude of fluid velocity across the turbine. For the diagram to be created [9] is used. The main design parameters are speed-work parameter, the stator exit angle of the absolute velocity. For the rotor row of the turbine, on the radial direction the design relation used is a free-vortex variation. The nomenclature used in the calculation of the diagram is from [9].

The definition of speed-work parameter is:

$$
\lambda=\frac{U^{2}}{l_{T}}
$$

where:

$U$ - Tangential velocity of the blade;

$l_{T}-$ Work provided by the turbine.

The torque created by the turbine depends on the variation of the tangential component of the absolute velocities. For maximum efficiency of the reaction turbine it is best that the absolute velocity exiting the 
blade row is axial, because all the tangential energy has been transformed to torque and to power. This is an important factor of optimization. The second factor of optimization is the Mach number in the stator row. The construction usually allows a Mach number of 1 in the stator, that is when the flow becomes supersonic and it cannot rise without a special geometry. The closer the Mach number is to 1 , the higher the efficiency.

When creating the diagram, it is necessary to allocate the wok on the turbine. Being a power turbine, the work is calculated by assuming that the pressure after the turbine is approximately equal to the ambient pressure. From the calculation it results a value of the work equal to $145.87 \mathrm{~kJ} / \mathrm{kg}$. From [5] it can be seen that all the work can be allocated to one stage, from two stages of the original engine. In the diagram there are two types of velocities regarding the fluid: absolute and relative velocity. The absolute velocity is relative to stationary parts of the engine, while the relative velocity is relative to the rotor of the turbine.

The first diagram calculated is at the mean radius. Then 8 more sections equally distanced from the mean radius are proposed and calculated. The mean radius velocities diagram can be seen in Fig. 5.

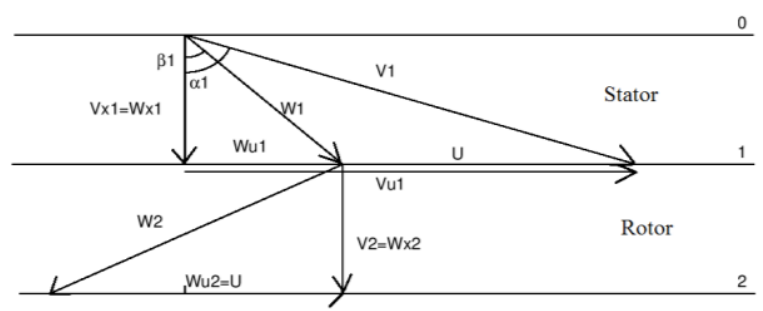

Fig. 5. Mean radius velocities diagram, $x-$ axial direction, $u-$ tangential direction, $\mathrm{V}$ - absolute velocity, $\mathrm{W}$ - relative velocity, $U-$ transport velocity of the blade row, $0-$ section before the stator row, 1 - section between the stator and the rotor row, 2 - section after the rotor row, $\alpha$ - absolute velocity angle with the axial direction, $\beta$ - relative velocity angle with the axial direction [8].

Although the Mach number of the absolute velocity exiting the stator must be 1 , the results in this case are not that good. The Mach numbers in the sections calculated are seen in Table 2.

So, the first part of the design process is finished. For the next part, the blade airfoil geometrical design a calculation method proposed is creating the airfoil of the blade. Initially the number of blades for the said stage for both the stator and the rotor are calculated by assuming the axial chord of the row, the axial distance between the leading-edge row line and the trailing edge row line. For that axial solidity which represents the ratio between the axial chord to the spacing, and is calculated with equation (6) the optimal axial solidity is calculated while assuming that the Zweifel coefficient is 0.8 because from [9] this value is associated with a maximum efficiency of the blade row.

$$
\sigma_{x}=\frac{2}{\psi_{z}} \frac{\cos \alpha_{2}}{\cos \alpha_{1}} \sin \left(\alpha_{1}-\alpha_{2}\right)
$$

- $\quad \sigma_{\mathrm{z}}-$ axial solidity;

- $\quad \psi_{z}-$ Zweifel coefficient;

- $\quad \alpha_{1}, \alpha_{2}-$ angle between the row absolute velocity for the stator, and relative for the rotor, and the row axial direction.

After an initial blade number is calculated it is rounded to the upper value and using the same axial solidity the final axial chord and spacing are calculated and the critical section, "o", of the blade row [9]. The number of blades calculated is 43 for stator row and 59 for rotor row.

Table 2. Mach number radial variation, $\mathrm{r} / \mathrm{r}_{\mathrm{m}}$ meaning the ratio between the section radius and the mean radius [8].

\begin{tabular}{|c|c|c|c|c|c|c|c|c|c|}
\hline $\mathrm{r} / \mathrm{r}_{\mathrm{m}}$ & 0.93352 & 0.95014 & 0.96676 & 0.98338 & 1 & 1.01662 & 1.03324 & 1.04986 & 1.06648 \\
\hline Mach number & 0.99755 & 0.98192 & 0.96686 & 0.95233 & 0.93831 & 0.92478 & 0.91171 & 0.89907 & 0.88686 \\
\hline $\mathrm{V}_{1}[\mathrm{~m} / \mathrm{s}]$ & 535.95 & 527.55 & 519.46 & 511.66 & 504.12 & 496.85 & 486.83 & 483.04 & 476.48 \\
\hline $\mathrm{W}_{1}[\mathrm{~m} / \mathrm{s}]$ & 279.53 & 268.65 & 258.30 & 248.48 & 239.21 & 230.48 & 222.31 & 214.71 & 207.70 \\
\hline $\mathrm{V}_{2}[\mathrm{~m} / \mathrm{s}]$ & 172.42 & 172.42 & 172.42 & 172.42 & 172.42 & 172.42 & 172.42 & 172.42 & 172.42 \\
\hline $\mathrm{W}_{2}[\mathrm{~m} / \mathrm{s}]$ & 335.19 & 339.59 & 344.01 & 348.45 & 352.91 & 357.38 & 361.87 & 366.38 & 370.90 \\
\hline$\alpha_{1}$ & 71.234 & 70.942 & 70.615 & 70.307 & 70 & 69.695 & 69.390 & 69.087 & 68.785 \\
\hline$\beta_{1}$ & 51.915 & 50.073 & 48.124 & 46.061 & 43.879 & 41.573 & 39.141 & 36.578 & 33.886 \\
\hline$\alpha_{2}$ & \multicolumn{7}{|c|}{5} & 0 & \multicolumn{5}{c|}{} \\
\hline$\beta_{2}$ & 59.043 & 59.487 & 59.920 & 60.342 & 60.753 & 61.154 & 61.545 & 61.926 & 92.298 \\
\hline
\end{tabular}




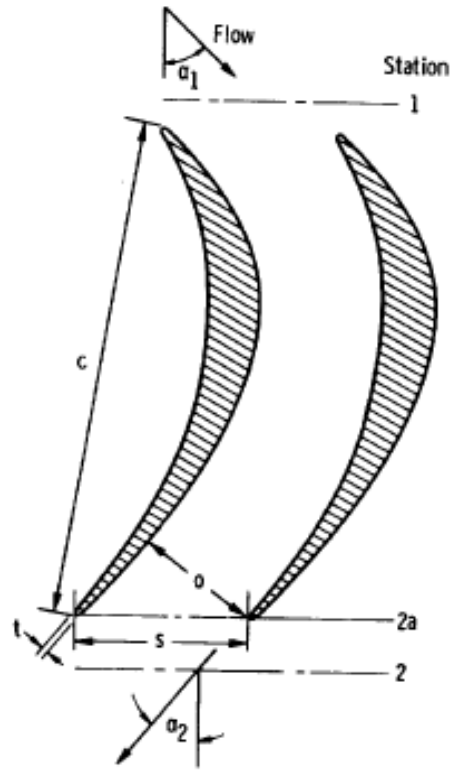

Fig. 6. Geometrical properties of the blade row [9].

After the row geometrical properties are calculated the blade airfoil design is realized. The model proposed for the design consists of generating the airfoil camber line, suction face, pressure face by generating three second order polynomials for each of the mentioned geometrical elements. These polynomials must be restricted and by imposing conditions. The model briefly described above is:

- $\quad$ Choosing leading edge, trailing edge radius and the stagger angle, also the angles for creating the tangencies of the pressure face and the suction face;

Creating functions and points that will create de conditions for constraining the airfoil. The elements necessary for the camber line are two points, those being the origin of the axis system $(0,0)$ and the point $(c, 0)$, where "c" is the chord of the profile and the inlet and outlet velocities written as two first straight-line functions, each passing through its respective point. As for the suction and pressure faces the elements are similar the difference being that the lines are changed in angle by half of a chosen value, 15 degrees for the leading edge and 5 degrees for the trailing edge and the points are now the intersection of the new lines and the leading and the trailing edge respectively. All these elements can be seen in Fig. 7;

- Transforming the elements in another axis system that is rotated relative to the origin of the first axis system, the angle of rotation between the two systems is to be calculated in a following step; and for the suction and pressure face tangency to the aforementioned lines;

- Imposing the conditions in the rotated axis system. The conditions are: tangency of the profile to the row inlet and outlet velocities and coincidence with the origin $(0,0)$ and the point $(\mathrm{c}, 0)$ for the camber line and for the suction and pressure faces tangency with the modified lines and the intersection points mentioned before;
- Creating a second order polynomials, in the rotated system, that satisfies the conditions mentioned; That is realized by writing the equations of these conditions, 4 in total, two tangencies and two coincidences for the camber line, using three equations deduce formulas for all the polynomial coefficients and then using the last unused equation to calculate the rotation angle of the axis system by applying the bisection method for that equation;

- Transforming the polynomial, which was generated in the rotated axis system and consists of a vector of points, back to the original system by rotating each point back to the original system;

a)

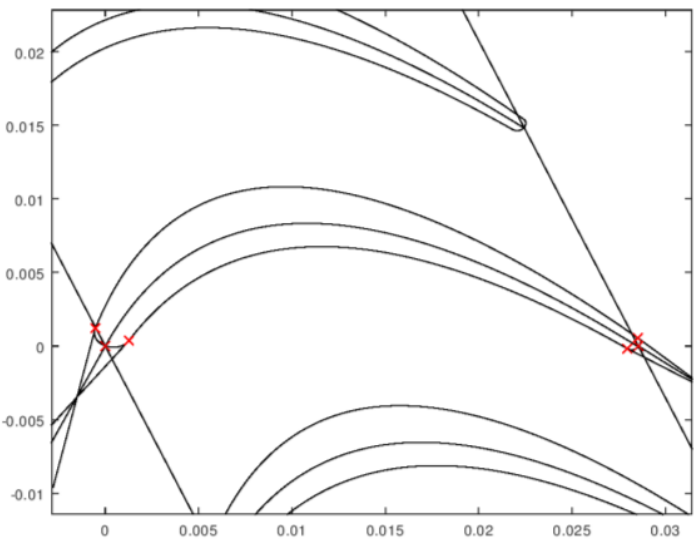

b)

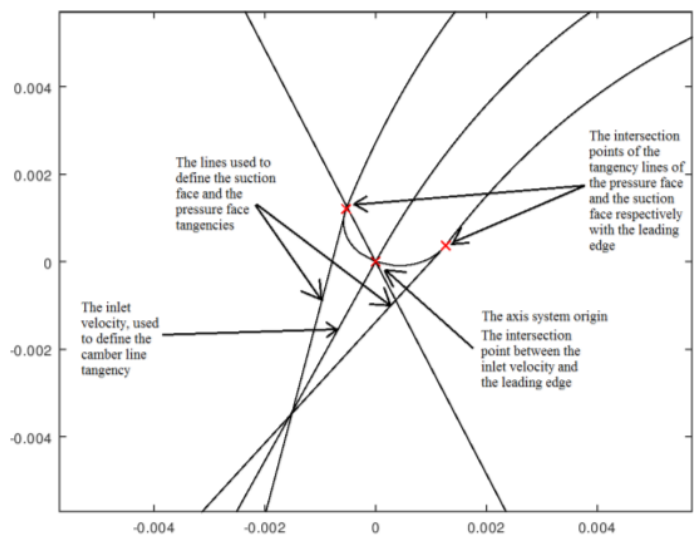

c)

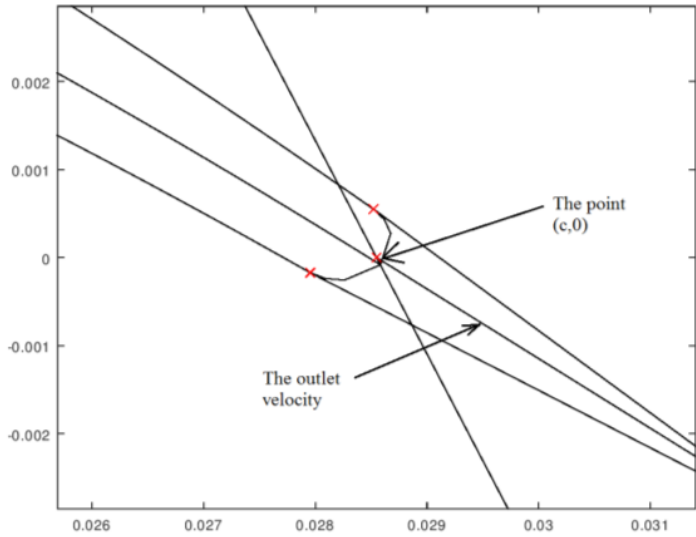

Fig. 7. The conditions presumed in the original axis system a) an overall representation, b) leading edge detail, c) trailing edge detail. 
a)

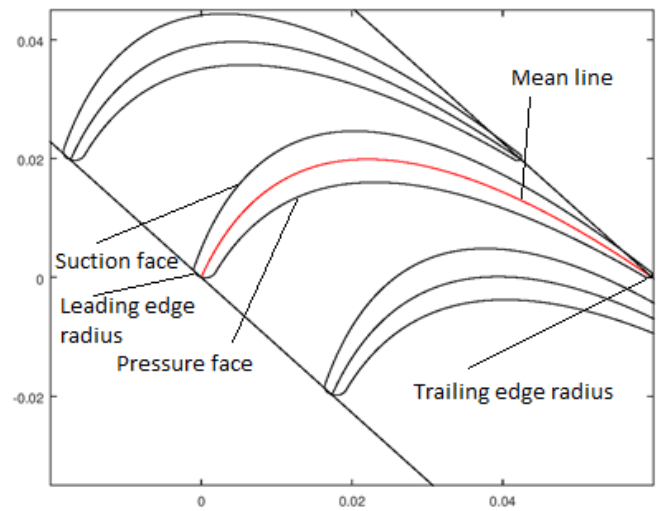

b)

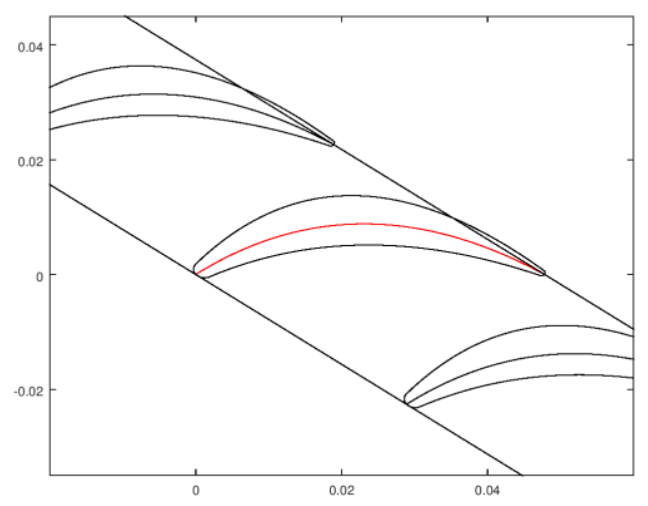

Fig. 8. Mean radius airfoils of the a) rotor row, b) stator row [8].

Then the calculations are done for all the sections and the airfoils are imported in CATIA.

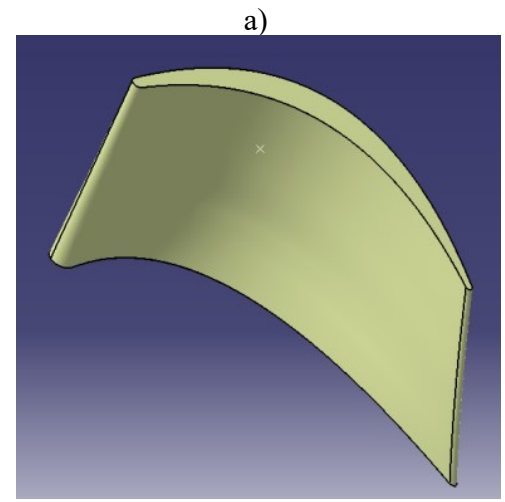

b)

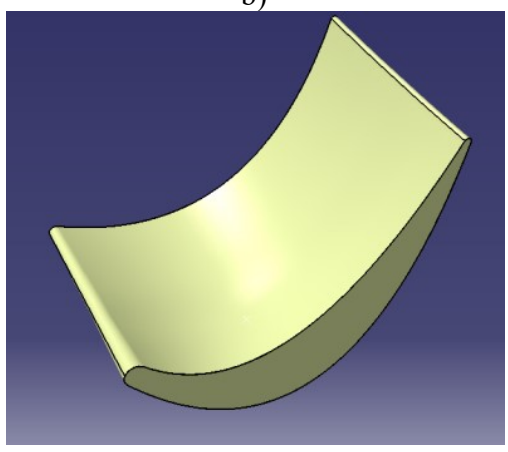

Fig. 9. The rotor blade realized in CATIA a) and b) two different perspectives of the blade [8].

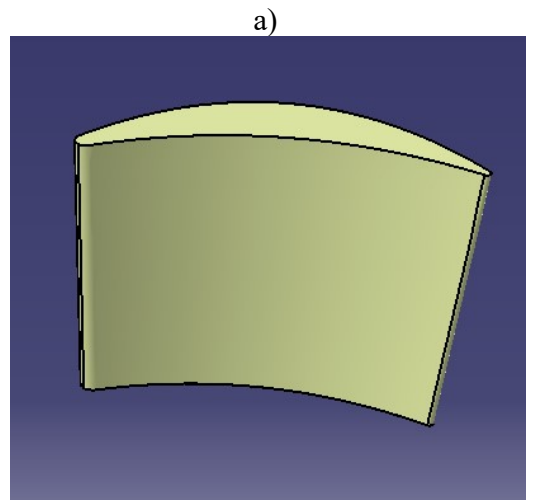

b)

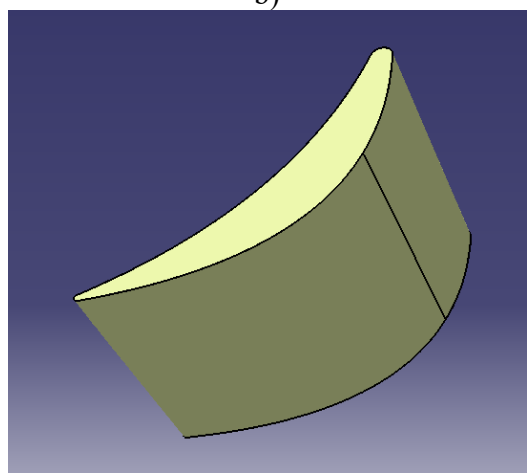

Fig. 10. Stator blade realized in CATIA a), and b) two different perspectives [8].

The design ends with the strength and vibrations calculation. This calculation is theoretical. The efforts presumed are traction of the blade, caused by the centrifugal force and bending caused by the pressure difference between the leading edge and the trailing of the blade row and the centrifugal force. The calculated values of the stresses, at a speed higher than the nominal one with an overspeed factor of 1.05 can be seen in Table 3. All the values are calculated in MPa.

The pressure and the centrifugal forces have been calculated using the formulas presented in [10]. The sum was also simply summed by analyzing [10].

By adding all the stresses created by the efforts and presuming a limit stress value equal to $180 \mathrm{MPa}$ from [10] the safety factor is 1.53 . That means that the turbine is properly dimensioned. If the factor is too big, that means that the turbine is too heavy, and the engine fuel consumption rises.

\section{Conclusion}

In conclusion the energy conversion analysis along the engine is very important for the optimization of the engine. It was observed the energy circuit inside the engine and more exactly the energy conversion in the gas turbine of the engine. The conversion analyzed initially suffers from losses. These losses are from documentation there are some methods of lowering them. The Mach number closer to 1 in the critical section of the stator is one of them, the axial exit of the absolute velocity from the rotor and the minimum mass of the 
turbine are all optimization factors that must be taken in consideration [9]. The applications results regarding the optimization criteria are mostly satisfying meaning that the turbine efficiency is acceptable.

The methods studied in the paper could be applied to redesign the aforementioned engine's turbine, TV2-117, for increased efficiency of the turbine and the entire engine. This method could be useful for aeroderivative use of this engine in cases where efficiency is the top priority, more than flight safety.
Also, we mention again that the algorithm for detailed turbine design can be used for other turbine applications. The envisaged one is for turbopump assembly for liquid engine rocket where the desire for high rate energy conversion might be even more demanding.

Table 3. Results of the stresses calculation [8].

\begin{tabular}{|c|c|c|c|c|c|c|c|c|c|}
\hline $\mathrm{r} / \mathrm{r}_{\mathrm{m}}$ & 0.93352 & 0.95014 & 0.96676 & 0.98338 & 1 & 1.01662 & 1.03324 & 1.04986 & 1.06648 \\
\hline $\begin{array}{c}\text { Traction } \\
\text { stress }\end{array}$ & 82.8323 & 75.4801 & 68.0678 & 57.4644 & 45.6786 & 35.0265 & 25.1754 & 13.8478 & 0 \\
\hline $\begin{array}{c}\text { Bending } \\
\text { stress }\end{array}$ & 41.2982 & 34.213 & 27.5654 & 20.2914 & 13.8409 & 8.0758 & 4.00477 & 1.148 & 0 \\
\hline $\begin{array}{c}\text { Total } \\
\text { stress }\end{array}$ & 117.546 & 103.828 & 91.1152 & 75.2983 & 58.7283 & 43.0825 & 29.3967 & 15.4473 & 0 \\
\hline
\end{tabular}

The presented study was performed in the frame of "NUCLEU 2018" Program (Ministry of Research and Innovation from Romania ctr. 11N/2018) and 3dRotor project (Romanian Space Agency STAR Program, ctr. 138/2017) within COMOTI Romanian Research and Development Institute for Gas Turbines.

\section{References}

[1] Meherwan P. Boyce, "Gas Turbine Engineering Handbook", Third Edition, Copyright (C) 2006, Elsevier Inc., ISBN 0-88415-732-6

[2] P.P. Walsh, P. Fletcher, "Gas Turbine Performance", Second Edition, (C) 2004 by Blackwell science Ltd., ISBN 0-632-06434-X

[3] H Cohen, GFC Rogers, HIH Saravanamuttoo, "Gas Turbine Theory", 4th EDITION, Longman Group Limited 1996, ISBN 0-58223632-0

[4] Cleopatra Cuciumita, Radu Mihalache, Daniel Olaru, Jeni Popescu and Valeriu Vilag, Design of a Liquid Hydrogen Turbine to Drive a Rocket Engine Turbopump, NCAS 2015 Conference, Bucharest

[5] V. Stanciu, "Motoare aeroreactoare. Îndrumar de proiectare", Editura Didactica si pedagogica, Bucuresti 1983 (V. Stanciu, "Jet propulsion engines. Pre-design handbook" (in Romanian), Polytechnic Institute of Bucharest, Bucharest, 1991);

[6] C. Levențiu, "Optimization of turbine engines. Modern systems for increasing gas turbine thrust", Course notes;

[7] V. Pimsner "Motoare aeroreactoare, vol. I", Editura Didactica si Pedagogica, București 1983 (V. Pimsner, "Jet propulsion engines, vol.
1" (in Romanian), Didactic and Pedagogic Publisher, Bucharest 1983);

[8] C. Dobromirescu, "Să se proiecteze turbina liberă pentru un motor similar cu TV2-117. Să se calculeze la rezistență și vibrații rotorul turbinei”, Universitatea Politehnica București, Bucuresti, 2018 (C. Dobromirescu, "Power turbine design for an engine similar with TV2117. Stress and vibration stress calculation of the turbine rotor" (in Romanian), Politehnica University of Bucharest, Bachelor degree thesis, 2018);

[9] A. J. Glassman, „Turbine design and aplication", Scientific and Technical information Program, Washington, DC, 1994;

[10] I. Manole, "Calculul de rezistență și vibrație a paletelor turbomotoarelor de aviație”, Academia Militară, Bucuresti, 1978 (I. Manole, „Resistance and vibration calculations of aviation turbine engines blades", Military academy, Bucharest, 1978 (in Romanian);

[11] "Descriere tehnică de şi instrucțiuni pentru exploatare TV2-117”, Secția de traduceri, București, 1971 („Technical description and use instructions for TV2-117, Translate section, Bucharest 1971). 